We should like to thank Professor S. G. Clayton, Mr. J. M. Brudenell, and Mr. R. M. Feroze for providing us with all the facilities necessary to complete the study. We are particularly grateful to Sister Toon and her staff in the short-stay ward at Dulwich Hospital. Miss C. A. Knight provided invaluable help with the statistics. The study received generous support from the Simon Population Trust.

\section{References}

1 Lewis, C., Lal, S., Branch, F., and Beard, R. W., British Medical fournal, $1971,4,606$.

2 Eysenck, S. B., and Eysenck, H. J., Life Sciences, 1964, 3, 1103.

Bone, M., Family Planning Services in England and Wales, p. 18 . London, H.M.S.O., 1973.

4 Brennan, M. E., and Opit, L.J., British Medical fournal, 1973, 3, Suppl., 19

${ }^{5}$ Gillett, P., personal communication.

${ }^{6}$ Fraser, A. C., and Watson, P. S., Practitioner, 1968, 201, 351.

\title{
Instability of Polymeric Skin Collagen in Osteogenesis Imperfecta
}

\author{
M. J. O. FRANCIS, ROGER SMITH, ROBERT J. BAUZE
}

British Medical fournal, 1974, 1, 421-424

\begin{abstract}
Summary
The structural polymeric collagen of the skin of 19 patients with osteogenesis imperfecta has been examined. In those with severe bone disease, who often have white sclerae, this collagen fraction is less resistant to depolymerization than that of age-matched controls, though the total amount is normal. In patients with less severe bone disease, whose sclerae are usually blue, the polymeric collagen may have normal stability but the total amount is reduced. These results suggest defective cross-linking of collagen in severe osteogenesis imperfecta.
\end{abstract}

\section{Introduction}

Excessive fragility of the bones, which is the main feature of osteogenesis imperfecta (Seedorff, 1949; Albright and Grunt, 1971; King and Bobechko, 1971; McKusick, 1972), is probably due to a disorder of bone matrix (Follis, 1953; Falvo and Bullough, 1973). Its other features, such as blue sclerae, thin skin, and abnormal teeth, suggest that the defect is a generalized one involving those tissues which contain collagen. Since the overall metabolism of collagen is similar in all tissues (Grant and Prockop, 1972), and since the structural collagen of bone cannot be extracted unchanged for biochemical study (Steven, 1970) we have examined the physical and chemical features of the structural polymeric collagen of the skin (Francis and Macmillan, 1971; Francis et al., 1973).

In vivo structural polymeric collagen is present in fibres composed of extensively cross-linked networks of collagen molecules. The introduction of these cross-links is an important feature of collagen maturation during life (Bailey, 1968) and confers on connective tissue many of its physical and biochemical properties. Though some of these crosslinks have been charaoterized and methods are available for their estimation (Tanzer, 1973) the chemistry of most of them, especially those present in the collagen fibres of adult tissues, is unknown. We have therefore had to adopt an indirect method for studying these cross-links (Steven, 1966; Francis and Macmillan, 1971). This consists in preparing a

Nuffield Department of Orthopaedic Surgery, Nuffield Orthopaedic Centre, Headington, Oxford OX3 7LD

M. J. O. FRANCIS, D.PHIL., Lecturer in Biochemistry

ROGER SMITH, M.D., M.R.C.P., First Assistant

ROBERT J. BAUZE, M.B., F.R.A.C.S., Girdlestone Scholar polymeric fraction which contains collagen fibres having both the amino-acid composition and the typical electron-microscopical appearance of purified collagen. This fraction constitutes the major proportion (over $60 \%$ ) of total skin collagen and remains extensively cross-linked. Its stability to depolymerization is easily measured and provides, in these purified samples, an indirect estimate of cross-links present between the collagen molecules.

Our results, which show in particular that this form of collagen is unstable in severe osteogenesis imperfecta, are briefly discussed in terms of modern knowledge of collagen structure.

\section{Subjects and Methods}

Nineteen patients with osteogenesis imperfecta (table I) and 54 normal controls were studied. (The data on 49 controls have been discussed elsewhere (Francis et al., 1973).) The patients are listed in order of increasing age and divided into groups according to the colour of the sclerae. This was estimated clinically and by photography against a standard colour chart as either blue or intermediate or white (normal). The severity of the bone disease was assessed by the age at onset and the approximate total number of fractures. In a larger clinical series it was clear that those with severe bone disease have a high incidence of severe scoliosis and are often unable to walk and that such patients tend to have sclerae of normal colour. Those with blue sclerae tend to have less severe bone disease. The division according to scleral colour was used here because of its simplicity and may need future modification.

The biopsy specimens were usually of a diamond or an elliptical shape. In 10 patients (cases $2,3,5,6,9,10,13$, 15-17) they were of constant area $\left(85 \mathrm{~mm}^{2}\right)$ and in the remaining nine they were not measured. Skin biopsy specimens were taken from behind the greater trochanter in all patients except cases $2,11,14$, and 19 . In cases 2,11 , and 14 skin was obtained from an operative site. In all elective biopsies performed during life the procedure was explained to the patients and their consent was obtained. Skin from one patient (case 1) was obtained after death. All specimens were analysed immediately or kept deep frozen at $-20^{\circ} \mathrm{C}$.

The procedure for analysis has been described previously (Francis and Macmillan, 1971; Francis et al., 1973). We measured the following collagen fractions: the total skin collagen (related to area and to fat-free dry weight), the proportion of collagen soluble in $5 \%(\mathrm{w} / \mathrm{v}) \mathrm{NaCl}$, and the polymeric or structural collagen. Two polymeric collagen fractions were obtained. The major fraction, which comprises 65 to $85 \%$ of total skin collagen in normal adults, contains collagen fibres that are larger and more stable than the minor 
Clinical and Biochemical Details of Patients with Osteogenesis Imperfecta

\begin{tabular}{|c|c|c|c|c|c|c|c|c|}
\hline \multirow{3}{*}{$\begin{array}{l}\text { Case } \\
\text { No. }\end{array}$} & \multirow{3}{*}{$\begin{array}{c}\text { Age } \\
\text { (Years) }\end{array}$} & \multicolumn{3}{|c|}{ Clinical } & & \multicolumn{3}{|c|}{ Biochemical } \\
\hline & & \multirow{2}{*}{ Sex } & \multirow{2}{*}{$\begin{array}{l}\text { Family } \\
\text { History }\end{array}$} & \multicolumn{2}{|c|}{ Fractures } & \multirow{2}{*}{$\begin{array}{c}\begin{array}{c}\text { Total Skin } \\
\text { Collagen } \\
(\mu \mathrm{g} / \mathrm{mg} \text { F.F... } \\
\text { Skin })\end{array} \\
\end{array}$} & \multicolumn{2}{|c|}{ Major Polymeric Collagen Fraction } \\
\hline & & & & Age at Onset & Approximate No. & & $\begin{array}{c}\text { Amount } \\
\left(\mu \mathrm{g} / \text { mg F.F. F. }_{\text {Skin })}\right.\end{array}$ & $\begin{array}{c}\text { Stability } \\
\text { (\% in Residue after } \\
\text { Cold Alkali) }\end{array}$ \\
\hline \multicolumn{9}{|c|}{ Blue Sclerae } \\
\hline $\begin{array}{r}1 * \\
2 \dagger \\
3 \\
4 \\
5 \\
6 \\
7 \\
8 \\
9 \\
10\end{array}$ & $\begin{array}{c}8 \text { days } \\
5 \\
17 \\
33 \\
35 \\
39 \\
40 \\
40 \\
56 \\
64\end{array}$ & $\begin{array}{l}\text { M. } \\
\text { F. } \\
\text { F. } \\
\text { F. } \\
\text { F. } \\
\text { F. } \\
\text { M. } \\
\text { F. } \\
\text { F. } \\
\text { M. }\end{array}$ & $\begin{array}{l}- \\
= \\
+ \\
+ \\
+ \\
+ \\
+ \\
+ \\
+\end{array}$ & $\begin{array}{l}\text { Birth } \\
13 \text { months } \\
5 \text { years } \\
2 \text { years } \\
18 \text { months } \\
2.3 \text { years } \\
6 \text { years } \\
12 \text { months } \\
2 \text { years } \\
14 \text { years }\end{array}$ & $\begin{array}{c}\text { Many } \\
\sim 5 \\
5 \\
12 \\
11 \\
\sim 25 \\
3 \\
28 \\
11 \\
3\end{array}$ & $\begin{array}{l}405 \\
515 \\
400 \\
445 \\
400 \\
595 \\
500 \\
570 \\
470 \\
425\end{array}$ & $\begin{array}{r}0 \\
82 \\
80 \\
131 \\
115 \\
270 \\
280 \\
185 \\
255 \\
215\end{array}$ & $\begin{array}{l}\overline{41} \\
54 \cdot 5 \\
74 \cdot 5 \\
88.5 \\
87 \\
80 \\
67 \\
83 \\
80.5\end{array}$ \\
\hline \multicolumn{9}{|c|}{ Intermediate (Pale Blue) Sclerae } \\
\hline $\begin{array}{l}11+ \\
12 \\
13\end{array}$ & $\begin{array}{l}11 \\
17 \\
25\end{array}$ & $\begin{array}{l}\mathrm{F} . \\
\mathrm{M}\end{array}$ & $\stackrel{+}{+}$ & $\begin{array}{l}18 \text { months } \\
4 \text { months } \\
\text { Birth }\end{array}$ & $\begin{array}{l}30 \\
45 \\
70\end{array}$ & $\begin{array}{l}630 \\
600 \\
485\end{array}$ & $\begin{array}{l}195 \\
440 \\
225\end{array}$ & $\begin{array}{l}58 \\
34.5 \\
83\end{array}$ \\
\hline \multicolumn{9}{|c|}{ White Sclerae } \\
\hline $\begin{array}{l}14 \dagger \\
15 \\
16 \\
17 \\
18 \\
19 \ddagger\end{array}$ & $\begin{array}{l}12 \\
19 \\
24 \\
25 \\
39 \\
56\end{array}$ & $\begin{array}{l}\text { M. } \\
\text { M. } \\
M . \\
M . \\
\text { M. } \\
\text { F. }\end{array}$ & $\begin{array}{l}- \\
\pm \\
\overline{-} \\
+ \\
+\end{array}$ & $\begin{array}{l}\text { Birth } \\
3 \text { years } \\
\text { Birth } \\
\text { Birth } \\
13 \text { months } \\
7 \text { years }\end{array}$ & $\begin{array}{c}50 \\
60 \\
30 \\
\text { Many } \\
>100 \\
12\end{array}$ & $\begin{array}{l}405 \\
525 \\
575 \\
660 \\
610 \\
490\end{array}$ & $\begin{array}{r}55 \\
410 \\
250 \\
450 \\
490 \\
145\end{array}$ & $\begin{array}{l}58 \\
32 \\
36 \\
55 \cdot 5 \\
54 \\
\end{array}$ \\
\hline
\end{tabular}

-Postmortem sample.

teg sample taken at operation.

F.F.D.W. = Fat-free dry weight.

fraction (normally about $2.5 \%$ of total collagen in adults and up to $15 \%$ in infants). The resistance of the major fraction to depolymerization by pronase, heat, or cold alkali was measured (Francis and Macmillan, 1971; Francis et al., 1973) except in case 1, where no major fraction was obtained and the chemical stability of the minor fraction was measured. Results are given only for depolymerization by cold alkali $\left(2.0 \mathrm{M} \mathrm{NaOH}\right.$ for six days at $\left.4^{\circ} \mathrm{C}\right)$, which solubilizes some of the originally insoluble polymeric collagen sample. This was measured and the results are expressed as residue/total as a percentage. Collagen was calculated from hydroxyproline $x$ $7 \cdot 1$, measured by the method of Bergman and Loxley (1970).

\section{Results}

The total amount of collagen in the skin, expressed in relation to fat-free dry weight, and the amount of the major polymeric collagen fraction which could be extraoted from it are shown in the table and in fig. 1 .

The polymeric collagen from both controls and patients consisted of collagen fibres with the amino-acid composition and electron-microscopical appearance typical of purified collagen. No adhering electron-dense material was present and contamination with proteoglycans was low (less than 5 mol hexosamine/mol collagen). Differences in the distribution of fibre size and in the fine band struoture of the polymeric collagen samples extracted from some patients were noted and will be discussed elsewhere.

In control subjects the values for total and polymeric oollagen did not differ appreciably between the ages of 15 and 75 years. In the four patients below the age of 15 years values were compared with those for age-matched controls. In patients above the age of 15 the group with blue sclerae (and mild bone disease) showed a significant reduction ( $P$ $<0.001)$ in total skin collagen. This difference is significant when the group is taken irrespective of sex and when females alone are considered (females have less skin collagen than males, and of the eight patients aged over 15 years in the blue solerae group six were women). The decrease in total skin collagen in the group with blue sclerae was accounted for by a decrease in the polymeric fraction, which was significantly less than the control values $(P<0.001)$. Both total skin col-
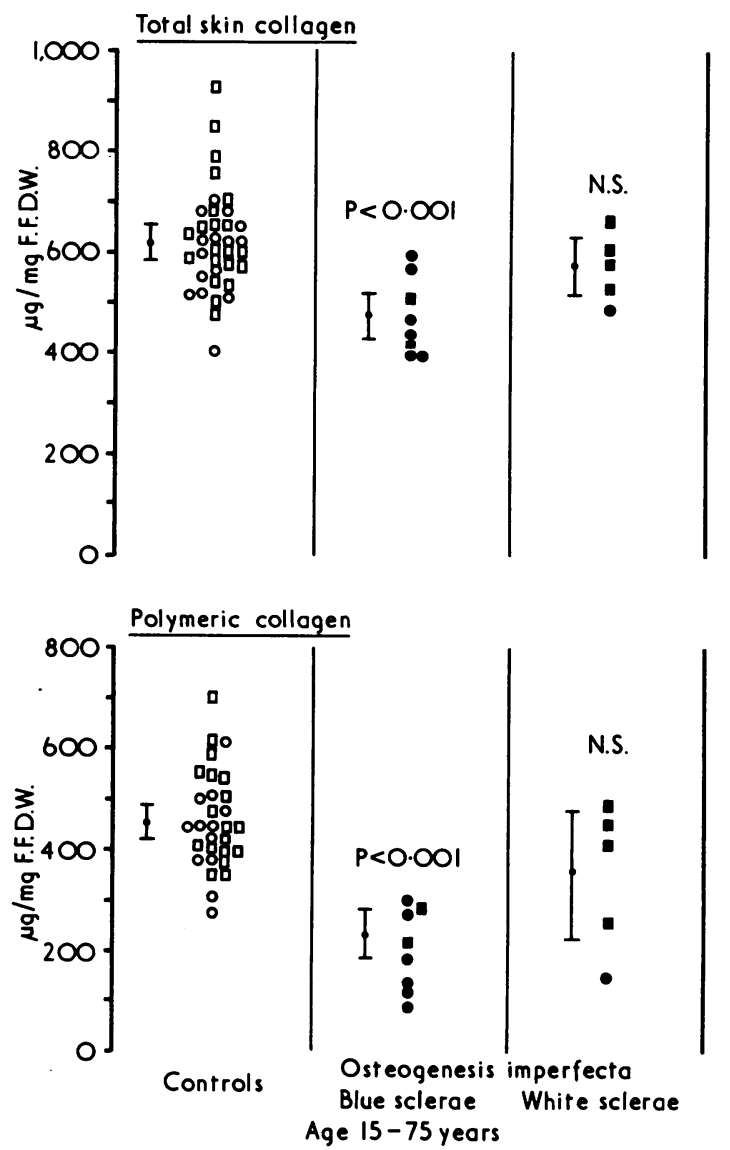

FIG. 1-Amount of total collagen and its major polymeric collagen fraction expressed as $\mu \mathrm{g} / \mathrm{mg}$ fat-free dry weight (F.F.D.W.) of skin from controls and patients with osteogenesis imperfecta with either blue or white sclerae aged 15-75 years. Males are shown as squares and females as circles. Means \pm 2 S.E. of mean are given for each group. $P$ values are for differences between means of control groups and patient groups. N.S. = Not significant.

iagen and polymeric collagen were significantly less in the group with blue sclerae than in those with white sclerae 
$(P<0.05)$. In the small group with white sclerae the values for total and polymeric collagen were variable but as a w! sle did not differ significantly from normal. Among the patients below the age of 15 years, case 14 showed a reduction in total and polymeric collagen; in cases 1 and 2 the polymeric fraction alone was decreased. The propontion of collagen which was soluble in $5 \% \mathrm{NaCl}$ was within the normal range except in cases 3 and 6 .

The stability of the major polymeric collagen fraction to depolymerization is expressed in the table and in fig. 2 as a percentage of the initial sample which remained in the residue after exposure to cold alkali. The control values are represented individually and as mean values \pm 2 S.D. for various age groups. In case 1 insufficient major polymeric collagen was obtained for stability studies but the minor fraction was of normal stability. In case 19 the major fraction was stable to pronase followed by heat treatment but there was insufficient to measure the stability to cold alkali. The polymeric collagen of patients with white sclerae (cases 14 to 18) was less stable than normal to cold alkali, and individual patients with blue sclerae had polymeric collagen of normal stability. Those patients over the age of 30 years with blue sclerae had a mean stability significantly less than controls $(P<0.01)$.

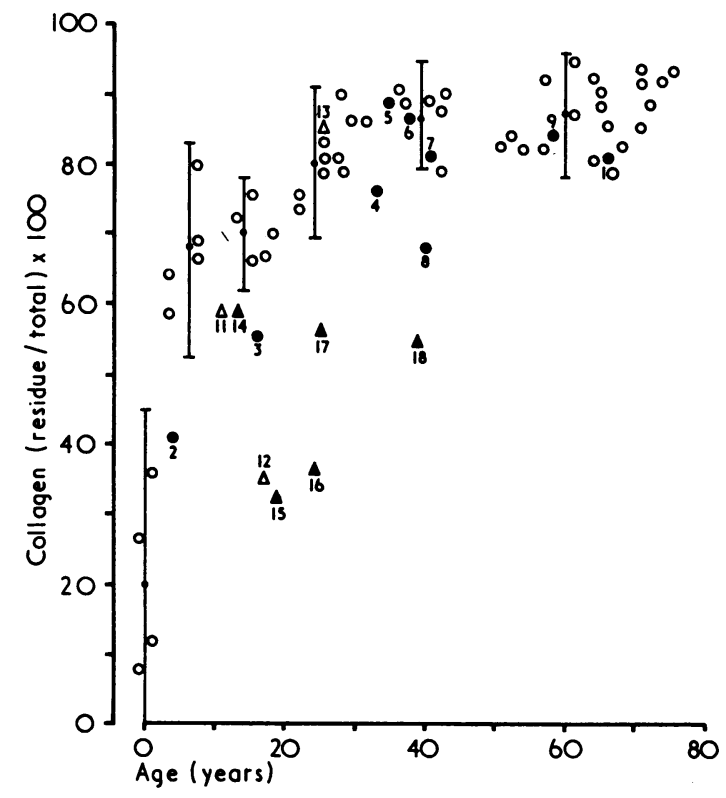
FIG. 2 - Changes with age in stability of polymeric collagen extracted from
skin of controls (o) and of patients with osteogenesis imperfecta with blue sclerae (O), intermediate (pale blue) sclerae $(\Delta)$, and white sclerae $(\Delta)$. sclerae (O), intermediate (pale blue) sclerae $(\triangle)$, and white sclerae ( alkali $\left(2.0 \mathrm{M} \mathrm{NaOH}\right.$ for six days at $4^{\circ} \mathrm{C}$ ) is expressed as percentage of total collagen. Means \pm 2 S.D. are given for controls in age ranges $0-3,4-9,10-19$, $20-29,30-49$, and 50-75 years.

In the blue sclerae group the patient with most fractures (case 8) had the least stable collagen; in the white sclerae group the patient with least fractures (case 19) had polymeric collagen which was normally stable to pronase and heat.

Thus most of the patients had abdominal skin collagen. Only two (cases 7 and 9) had no significant collagen abnormality, and both had mild bone disease.

\section{Discussion}

It is widely known that the manifestations of osteogenesis imperfecta are many and varied. Yet much has been written about the biochemistry and pathology of this condition with- out reference to the alinical features. Our results suggest that the known clinical heterogeneity of patients with the disorder is reflected in the different types of collagen abnormality observed. Interpretation of our results therefore depends as much on an accurate clinical assessment of the patients as on a knowledge of collagen chemistry. In our experience patients with osteogenesis imperfecta seem to fall into two groupsnamely, those with mild bone disease and blue sclerae and those with severe bone disease and white sclerae (Smith and Francis, 1973). The extremes of these are so different as to suggest different disorders, but it may be that they all form a continuous range. So far as our present work is concerned this simple division correlates well with our biochemical findings. Patients with blue sclerae tend to have a reduced amount of collagen which is often of normal stability, and those with white sclerae tend to have a normal amount with reduced stability.

To interpret the possible significance of these findings it is necessary to take note of recent work on collagen (Grant and Prockop, 1972). In life the extracellular fibre formed from collagen molecules is stabilized by the progressive introduction of chemical cross-links between adjacent molecules, the nature of which is only pantly known (Robins et al., 1973). The type of cross-links as well as the collagen molecule itself can differ in fetal and adult tissues (Barnes et al., 1971; Miller et al., 1971; Bailey and Robins, 1972) and in bone and cartilage (Miller, 1971). In our studies a gross decrease in polymeric collagen stability, as in those patients with white sclerae, probably indicates a reduotion in the number of collagen cross-links or change in their type, whereas a less pronounced decrease need not (Francis and Macmillan, 1971; Francis et al., 1973).

These results will need to be confirmed by direot measurement of collagen cross-links, for which some methods are already available (Bailey, 1968; Tanzer, 1973).

A number of mechanisms could account for the observed abnormalities in osteogenesis imperfecta. For example, the normal changeover from the fetal to the adult type of collagen could be delayed or the production of adult collagen suppressed. Alternatively a genetic abnormality could cause a change in the amino-acid sequence, the effects of which would vary with its position.

Our preliminary postulate is that we are seeing two different manifestations of an inherited disonder which could be due to an abnormality in the amino-acid sequence of collagen. In one of these the production of normally cross-linked collagen is reduced; there is mild bone disease of an osteoporotic sort; and the sclerae are blue since they have less collagen than normal and the blue colour of the choroid shows through it. In the other manifestation the collagen is unstable though produced in normal amounts; the sclerae contain normal amounts of collagen and are therefore of normal colour; but the unstable collagen produces a very defective bone matrix and sevene bone disease.

We are grateful to the physicians and surgeons who kindly allowed us to study their patients, and to the patients themselves for their willing collaboration. We thank Mrs. J. J. Pointon for her excellent technical help. This work was done during the tenure of a Girdlestone Scholarship by R.J.B. and was supported by grants to M.J.O.F. from the Medical Research Council and to R.S. from the Wellcome Trust.

\section{References}

Albright, J. A. and Grunt, J. A. (1971). Journal of Bone and foint Surgery, 53A, 1415 .

Bailey, A. J. (1968). In Comprehensive Biochemistry, ed. M. Florkin and E. H. Stotz, vol. 26B, p. 297. Amsterdam, Elsevier.

Bailey, A. J., and Robins, S. P. (1972). Federation of European Biochemical Society Letters, 21,330

Barnes, M. J., Constable, B. J., Morton, D. F., and Kodicek, E. (1971). Biochemical fournal, 125, 433. 
Bergman, I., and Loxley, R. (1970). Clinica Chimica Acta, 27, 347.

Falvo, K. A., and Bullough, P. G. (1973). Fournal of Bone and Foint Surgery, 55A, 275.

Follis, R. H. (1953). Bulletin of the fohns Hopkins Hospital, 93, 386.

Francis, M. J. O., and Macmillan, D. C. (1971). Biochimica et Biophysica Acta, 251, 236.

Francis, M. J. O., Smith, R., and Macmillan, D. C. (1973). Clinical Science, 44, 429 .

Grant, M. E., and Prockop, D. J. (1972). New England Fournal of Medicine, $83,194,242$, and 291 .

King, J. D., and Bobechko, W. P. (1971). Fournal of Bone and Foint Surgery, $53 \mathrm{~B}, 72$.

McKusick, V. (1972). Heritable Disorders of Connective Tissue, 4th edn. St. Louis, Mosby.
Miller, E. J. (1971). Biochemistry, 10, 1652.

Miller, E. J., Epstein, E. H., and Piez, K. A. (1971). Biochemical and Biophysical Research Communications, 42, 1024.

Robins, S. P., Shimokomaki, M., and Bailey, A. J. (1973). Biochemical Fournal, 131, 771 .

Seedorff, K. S. (1949). Osteogenesis Imperfecta: A Study of Clinical Features and Heredity based on 55 Danish Families comprising 180 Affected Individuals. Copenhagen, Ejnar Munksgaard.

Smith, R., and Francis, M. J. O. (1973). Quarterly fournal of Medicine, 42, 833.

Steven, F. S. (1966). Biochimica et Biophysica Acta, 130, 196.

Steven, F. S. (1970). Chemistry and Molecular Biology of the Intercellular Matrix, ed. E. A. Balazs, vol. I, p. 43. New York, Academic Press.

Tanzer, M. L. (1973). Science, 180, 561.

\title{
Observations on Drug Prescribing in Rheumatoid Arthritis
}

\author{
P. LEE S. J. AHOLA， D. GRENNAN， P. BROOKS, W. WATSON BUCHANAN
}

British Medical fournal, 1974, 1, 424-426

I firmly believe that if the whole material medica, as now used, could be sunk to the bottom of the sea, it would be all the better for mankind, and all the worse for the fishes.-OLIVER WeNDALl Holme. ${ }^{1}$

\section{Summary}

A total of 125 patients with rheumatoid arthritis were investigated about their drug therapy before referral to a specialist centre. Most referrals were from general practitioners. Only 47 of the patients had received salicylates as the first drug and 18 had never had them at all. Soluble aspirin was the preparation of salicylates most frequently prescribed (for 63 patients). Only 60 patients had been given an adequate dose and only 62 an adequate course of treatment with salicylates. In 28 patients salicylates had been stopped on account of side efiects. About one-third of the patients had been prescribed oral corticosteroids.

The referral letters were poor in giving details of past and present drug therapy, and there were serious omissions in reporting of previous side effects.

Seventy-five general practitioners were asked to rate several currently marketed antirheumatic drugs in terms of effectiveness. Though prednisolone $15 \mathrm{mg}$ daily ranked higher than aspirin $4 \mathrm{~g}$ daily the difference was not significant. The study shows the inadequacies of drug prescribing for rheumatoid arthritis in the Glasgow area.

\section{Introduction}

Many analgesic and anti-inflammatory drugs may now be prescribed to relieve pain in rheumatoid arthritis. Nevertheless, the "sheet-anchor" of treatment is still salicylates. ${ }^{2-5} \mathrm{We}$ have found that many patients referred for consultation have not received salicylates as their first drug and many have never received them at all. We have therefore reviewed drug treatment in new referrals to this clinic and the information regarding drug

Centre for Rheumatic Diseases and University Department of Medicine, Glasgow Royal Infirmary, Glasgow G4 OEH

P. LEE, M.B., M.R.A.C.P., Senior Registrar in Rheumatology

S. J. AHOLA, M.D., Registrar

D. J. ARENNAN, M.B., M.R.C.P., Registrar

D. GRENNAN, M.B., M.R.C.P., Registrar

P. BROOKS, M.B., M.R.A.C.P., Registrar
W. WATSON BUCHANAN, M.D., F.R.C.P., Professor of Medicine therapy given in the referral letter. The results indicate an unsatisfactory state of drug prescribing in patients with rheumatoid arthritis in Glasgow.

\section{Patients and Methods}

We interviewed 125 patients, who were seen consecutively by one doctor, about their drug therapy before they were referred to the centre. The mean age of the patients was 50.6 \pm S.D. 15.6 years (range 13 to 82 years) and 93 were female. All had "definite" or "classical" rheumatoid arthritis according to the diagnostic criteria of the American Rheumatism Association." The mean duration of arthritis was $7 \cdot 2 \pm 7 \cdot 3$ years, with a range from one month to 31 years.

Each patient was questioned about the first drug prescribed for his arthritis, its dose and duration, and whether it gave rise to side effects; similar details were obtained for all other drugs prescribed. When the patient was uncertain about what drug he had been given he was asked to identify it from a display of available antirheumatic agents. When doubt still existed a letter was sent to the family doctor to verify the preparation given. In 13 patients the first drug prescribed could not be ascertained with certainty, and these patients were not included in the study. We also noted the source of patient referral and whether the accompanying letter mentioned previous and current drug therapy and its dosage-also whether side effects had resulted.

We recorded the preparation of salicylate which had been prescribed and whether salicylates were prescribed in proper dosage-that is, $3 \mathrm{~g}$ or more per day-and whether this was given a proper trial-three months or more. We noted also the reason for discontinuing salicylate therapy, any self-medication of analgesics, and the preparation and dosage of corticosteroid therapy.

To determine opinions on the effectiveness of available antirheumatic drugs we sent a questionnaire to 75 general practitioners in Glasgow chosen at random from the General Medical Service list of medical practitioners. They were asked to rate the effectiveness of a number of preparations on a fivepoint scale: totally ineffective 1 , ineffective 2 , moderately effective 3 , effective 4 , and highly effective 5 (see table VI). Forty-nine replies were received. A further 250 general practitioners were asked whether they approved of a proposed standard regimen of drug treatment consisting of initial treatment with salicylates $3 \cdot 5-4 \mathrm{~g}$ daily. Should the patient fail to tolerate or respond to salicylates indomethacin up to $150 \mathrm{mg}$ daily, benorylate $10 \mathrm{ml}$ twice a day, or phenylbutazone $300 \mathrm{mg}$ daily could be given. If this treatment failed then gold or penicillamine, corticosteroids, or immunosuppressive agents might be given but only in consultation with a rheumatologist. As adjuncts to treatment we recommended ibuprofen $1,200 \mathrm{mg}$ 